\title{
THE IMPACT OF DURATION OF ORGAN DYSFUNCTION ON THE OUTCOME OF PATIENTS WITH SEVERE SEPSIS AND SEPTIC SHOCK
}

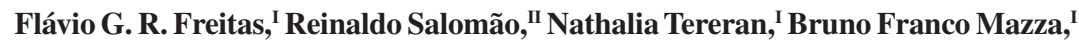 \\ Murillo Assunção, ${ }^{\mathrm{I}}$ Mirian Jackiu, ${ }^{\mathrm{I}}$ Haggeas Fernandes, ${ }^{\mathrm{I}}$ Flávia Ribeiro Machado ${ }^{\mathrm{I}}$
}

doi: $10.1590 / \mathbf{S 1 8 0 7 - 5 9 3 2 2 0 0 8 0 0 0 4 0 0 0 1 2}$

Freitas FGR, Salomão R, Tereran N, Mazza BF, Assunção M, Jackiu M, Fernandes H, Machado FR. The impact of duration of organ dysfunction on the outcome of patients with severe sepsis and septic shock. Clinics. 2008;63:483-8.

OBJECTIVES: This study aimed to assess the impact of the duration of organ dysfunction on the outcome of patients with severe sepsis or septic shock.

METHODS: Clinical data were collected from hospital charts of patients with severe sepsis and septic shock admitted to a mixed intensive care unit from November 2003 to February 2004. The duration of organ dysfunction prior to diagnosis was correlated with mortality. Results were considered significant if $\mathrm{p}<0.05$.

RESULTS: Fifty-six patients were enrolled. Mean age was $55.6 \pm 20.7$ years, mean APACHE II score was $20.6 \pm 6.9$, and mean SOFA score was 7.9 \pm 3.7 . Thirty-six patients $(64.3 \%)$ had septic shock. The mean duration of organ dysfunction was $1.9 \pm 1.9$ days. Within the univariate analysis, the variables correlated with hospital mortality were: age $(\mathrm{p}=0.015)$, APACHE II $(\mathrm{p}=0.008)$, onset outside the intensive care unit ( $\mathrm{p}=0.05)$, blood glucose control $(\mathrm{p}=0.05)$ and duration of organ dysfunction $(\mathrm{p}=0.0004)$. In the multivariate analysis, only a duration of organ dysfunction persisting longer than 48 hours correlated with mortality ( $\mathrm{p}=0.004$, OR: 8.73 (2.37-32.14)), whereas the APACHE II score remained only a slightly significant factor ( $\mathrm{p}=0.049$, OR: $1.11(1.00-1.23)$ ). Patients who received therapeutic interventions within the first 48 hours after the onset of organ dysfunction exhibited lower mortality $(32.1 \%$ vs. $82.1 \%, \mathrm{p}=0.0001)$.

CONCLUSIONS: These findings suggest that the diagnosis of organ dysfunction is not being made in a timely manner. The time elapsed between the onset of organ dysfunction and initiation of therapeutic intervention can be quite long, and this represents an important determinant of survival in cases of severe sepsis and septic shock.

KEYWORDS: Sepsis diagnosis. Sepsis management. Surviving Sepsis Campaign. Intensive care. Infection.

\section{INTRODUCTION}

The incidence of sepsis has increased dramatically over the past several decades. A number of factors may have played a role in this increase, such as advanced patient age, increased numbers of diagnostic and therapeutic procedures, frequent use of immunosuppressive drugs, and the growing number of multidrug-resistant bacterial infections, especially within the nosocomial environment. ${ }^{1}$ Sepsis is a common

IDisciplina de Anestesiologia, Dor e Terapia Intensiva, Universidade Federal de São Paulo - São Paulo/SP, Brazil.

II Departamento de Infectologia, Universidade Federal de São Paulo - São Paulo/SP, Brazil.

Email: fmachado.dcir@epm.br

Received for publication on May 05, 2008

accepted for publication on May 19, 2008 condition in intensive care units (ICU), affecting about 37\% of admitted patients. ${ }^{2}$

In the United States, 215,000 deaths are believed to result from severe sepsis annually, a figure that matches the number of deaths due to acute myocardial infarction. ${ }^{3}$ Although the disease-associated mortality rate for sepsis is beginning to decline, it remains unacceptably high, reaching $30-50 \%$ for patients with severe sepsis. ${ }^{4}$ In Brazil, sepsis-related mortality rates are also very high, ranging from $34.7 \%$ in patients with sepsis to $52.2 \%$ in patients with septic shock. ${ }^{5}$

The social and economic burden associated with the disease is just as alarming. According to American data, about US $\$ 22,000$ is spent per septic patient, a figure that may be higher for intensive care patients. ${ }^{3} \mathrm{~A}$ Brazilian study found a mean cost of US $\$ 9,632$ per ICU patient. ${ }^{6}$ Moreover, severe sepsis and septic shock survivors were described as 
experiencing a high long-term mortality rate and a significant drop in their health-related quality of life. ${ }^{7,8}$

Encouraging data from recent studies suggest that it may be possible to ameliorate this situation. ${ }^{9-13}$ However, the incorporation of new evidence into medical practice is a slow process. The Surviving Sepsis Campaign (SCC), sponsored by the Society of Critical Care Medicine, the European Society of Intensive Care Medicine, and the International Sepsis Forum, represents an effort to facilitate a rapid change in the standard of care in the management of sepsis based on the quality of available published data. ${ }^{14}$ The severe sepsis bundles (SSB) provide the core of the SSC implementation phase. ${ }^{15}$

Unfortunately, in a significant number of patients, the diagnosis of severe sepsis is not made at the onset of organ dysfunction. Early and accurate detection and an increased use of appropriate treatments and procedures will be essential if SSC is to achieve its goal of reducing mortality from severe sepsis by $25 \%$ in five years. This study aimed to assess the impact of the duration of organ dysfunction (DOD) prior to diagnosis on the mortality of patients with severe sepsis and septic shock admitted to the ICU.

\section{MATERIALS AND METHODS}

\section{Population}

Inpatients in a 16-bed mixed ICU at a Brazilian teaching hospital were assessed from November 2003 to February 2004, and those diagnosed with severe sepsis or septic shock during their ICU stay were enrolled. Criteria to define sepsis and associated conditions followed those proposed by the ACCP/SCCM (American College of Chest Physicians/ Society of Critical Care Medicine). ${ }^{16}$ The definition of severe sepsis was based on the criteria stated in Table 1. All patients were prospectively enrolled in a clinical trial that aimed to

Table 1 - Criteria for definition of organ dysfunction

Arterial hypotension (SBP $<90 \mathrm{~mm} \mathrm{Hg}$, MAP $<70$, or SBP decrease $>40$ $\mathrm{mm} \mathrm{Hg}$ )

Arterial hypoxemia $\left(\mathrm{PaO}_{2} / \mathrm{FiO}_{2}<300\right)$

Acute oliguria (urine output $<0.5 \mathrm{~mL} / \mathrm{kg} / \mathrm{hr}$ for at least $2 \mathrm{hrs}$ ) or creatinine $>2.0 \mathrm{mg} / \mathrm{dL}$

Altered mental status (Glasgow coma scale <13)

Thrombocytopenia (platelet count $<100,000$ cells $/ \mathrm{mm}^{3}$ )

Hyperbilirubinemia (plasma total bilirubin $>2.0 \mathrm{mg} / \mathrm{dL}$ or $35 \mathrm{mmol} / \mathrm{L}$ )

Unexpected metabolic acidosis $(\mathrm{pH}<7.30$ or base excess $>5.0 \mathrm{mEq} / \mathrm{L})$

Coagulation abnormalities (INR $>1.5$ or aPTT $>60 \mathrm{sec}$ )

SBP, systolic blood pressure; MAP, mean arterial pressure; INR, international normalization ratio; aPTT, activated partial thromboplastin time. assess the cost of sepsis in Brazil (COSTS). ${ }^{6}$ Patients under the age of 18 years were excluded. The institutional Research and Ethics Committee of the institution approved the study. Patients or their legal representatives signed the informed consent form, agreeing to the data collection.

\section{METHODS}

Duration of organ dysfunction was assessed and defined as the time elapsed between the chart entry of laboratory and/or clinical alterations that could have represented the onset of organ dysfunction, as defined in Table 1, and the moment that sepsis was diagnosed by the healthcare team. The moment of diagnosis was defined as the time at which a possible diagnosis of severe sepsis or septic shock was entered into the chart, or at which steps were taken to treat any organ dysfunction considered secondary to the infection. For patients with severe sepsis admitted from the Emergency Department, the moment of hospital admission was considered the beginning of organ dysfunction.

Demographic data, severity of illness (APACHE II score), organ failure assessment (SOFA score), management of severe sepsis, and duration of organ dysfunction (DOD) were obtained by either chart analysis or consultation of the COSTS study database. Management of severe sepsis and septic shock was assessed based on therapeutic and diagnostic interventions received in the first 24 hours following the moment of diagnosis. Analysis was based on the current SSC proposals, according to the six-hour and 24-hour sepsis bundles recommendations, following local adjustments. The data obtained were correlated with mortality.

\section{Statistical analysis}

Initially, a descriptive analysis was carried out. Mortality was then analyzed in relation to demographic characteristics, severity of illness (APACHE II score), organ dysfunction assessment (SOFA score), compliance with the SSB, and DOD. The Student's t-test was used for analysis of quantitative variables, the chi-square test for qualitative variables. Variables with p-values less than 0.10 were included in multivariate analysis by logistic regression.

Additional analysis was performed in which DOD was considered a categorized variable, with patients classified in Group 1 when a diagnosis was made or an intervention performed within the first 48 hours after the onset of organ dysfunction, and in Group 2 when these actions occurred after 48 hours. As mortality rates were significantly different between these two groups, the groups were compared for known risks factors that could have explained the difference 
in mortality, using Student's t and chi-square tests.

Statistical analysis was performed using SPSS software, version 15.0 for Windows, and results with p-values less than 0.05 were considered significant.

\section{RESULTS}

Fifty-six patients were enrolled, 29 of whom were male (51.8\%). The mean age was $55.5 \pm 20.8$ years, the mean APACHE II score at admission was $20.6 \pm 6.9$, and the mean SOFA score at the moment of diagnosis was $7.9 \pm$ 3.7. Surgical cases represented $53.6 \%$ of the sample. Forty patients $(71.4 \%)$ acquired the infection within the hospital environment. In most cases (75\%), severe sepsis or septic shock initially occurred in non-ICU units. Thirty-six patients (64.3\%) were admitted to the ICU due to a presumed or confirmed infectious condition. Baseline characteristics are displayed in Table 2.

Regarding the presence of organ dysfunction, 46 patients $(82.1 \%)$ presented with two or more organs affected at the time of diagnosis. The mean time elapsed between evidence of the onset of dysfunction and the moment of diagnosis was $1.9 \pm 1.9$ days, and 11 patients $(19.6 \%)$ had experienced dysfunction of at least one organ for five days or longer.

Table 2 - Baseline patient characteristics

\begin{tabular}{lcccc}
\hline Variable & $\begin{array}{c}\text { All patients } \\
\mathrm{n}=56\end{array}$ & $\begin{array}{c}\text { Group I } \\
\mathrm{N}=28\end{array}$ & $\begin{array}{c}\text { Group II } \\
\mathrm{n}=28\end{array}$ & p-value* \\
\hline Age (yrs) & $55.6 \pm 20.7$ & $50.1 \pm 20.8$ & $61.1 \pm 19.5$ & 0.05 \\
\hline Gender & $29(51.8 \%)$ & 17 & 12 & 0.18 \\
$\begin{array}{l}\text { Male } \\
\text { Female }\end{array}$ & $27(48.2 \%)$ & 11 & 16 & \\
\hline APACHE II score & $20.6 \pm 6.9$ & $19 \pm 7.6$ & $22.1 \pm 5.7$ & 0.09 \\
\hline SOFA score & $7.9 \pm 3.7$ & $7.9 \pm 3.5$ & $7.9 \pm 3.9$ & 0.97 \\
\hline Category & & & & \\
Medical & $26(46.4 \%)$ & 15 & 11 & 0.28 \\
Surgical & $30(53.6 \%)$ & 13 & 17 & \\
\hline Patient location & & & & \\
Hospital ward & $42(75 \%)$ & 20 & 22 & 0.56 \\
ICU/ED & $14(25 \%)$ & 8 & 6 & \\
\hline $\begin{array}{l}\text { Infectious } \\
\text { classification }\end{array}$ & $16(28.6 \%)$ & 11 & 5 & 0.08 \\
$\begin{array}{l}\text { Community-acquired } \\
\text { Hospital-acquired }\end{array}$ & $40(71.4 \%)$ & 17 & 23 & \\
\hline
\end{tabular}

\begin{tabular}{|c|c|c|c|c|}
\hline \multicolumn{5}{|l|}{ Sepsis classification } \\
\hline Severe sepsis & $20(35.7 \%)$ & 8 & 12 & 0.27 \\
\hline Septic shock & $36(64.3 \%)$ & 20 & 16 & \\
\hline $\begin{array}{l}\text { Number of organs } \\
\text { affected }\end{array}$ & $2.6 \pm 1.2$ & $2.75 \pm 1.2$ & $2.5 \pm 1.2$ & 0.45 \\
\hline Mortality & $57.1 \%$ & $32.1 \%$ & $82.1 \%$ & 0.0001 \\
\hline
\end{tabular}

Patients in the ICU had a shorter DOD $(1.2 \pm 1.3)$ than those coming from other ward units $(2.2 \pm 2.0)$, although this difference was not statistically significant $(\mathrm{p}=0.11)$. Among the patients coming from other hospital wards, $26.7 \%$ had experienced organ dysfunction for more than five days. Surgical patients also had a longer DOD than medical patients, although again, this difference was not statistically significant $(2.23 \pm 2.07$ vs. $1.46 \pm 1.65, \mathrm{p}=0.134)$.

Overall, mortality was $57.1 \%$. The mortality rate for patients with an initial diagnosis of severe sepsis was $45 \%$, and it was $63.9 \%$ for patients diagnosed with septic shock ( $\mathrm{p}=0.17$ ). Patients with a longer DOD showed higher mortality. As shown in Figure 1, mortality varied from 33.3\% when intervention was started within the first 24 hours of organ dysfunction, to $84.5 \%$ when four or more days elapsed before treatment was initiated, with a sharp increase after 48 hours of organ dysfunction. In the univariate analysis, variables associated with mortality were: age $(p=0.015)$, APACHE II ( $p=0.008)$, onset of severe sepsis or septic shock outside the ICU ( $\mathrm{p}=0.05)$, and DOD ( $\mathrm{p}=0.0004)$ (Table 3 ). Among the diagnostic and therapeutic interventions carried out, only blood glucose control was correlated with reduced mortality $(\mathrm{p}=0.05)$. In contrast, the use of steroids was correlated with increased mortality $(\mathrm{p}=0.05)$. These variables were included in the multivariate analysis. Because there was no difference in mortality for patients with a DOD of zero or one day $(\mathrm{p}=0.49)$, or between patients with a DOD of two, three, or four days $(\mathrm{p}=0.66)$, this variable was categorized as either less than 48 hours or more than 48 hours of organ dysfunction. Only a DOD of greater than 48 hours correlated with mortality ( $\mathrm{p}=0.004$, OR: 8.735 (2.374-32.14)), whereas the APACHE II score proved to be a slightly significant factor, with $\mathrm{p}=0.049$, OR=1.11 (1.00-1.234).

Twenty-eight patients $(50 \%)$ underwent therapeutic

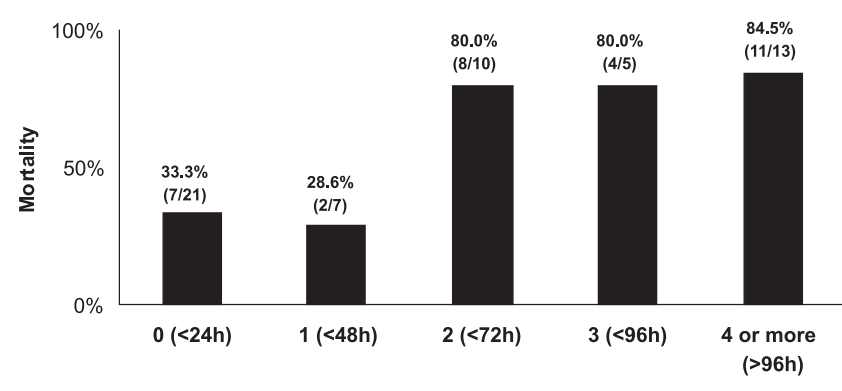

Figure 1. Mortality related to duration of organ dysfunction (DOD). DOD represents the time elapsed from the onset of organ dysfunction to the time of diagnosis in patients with severe sepsis and septic shock. As there was no difference in mortality between patients with a DOD of zero or one day $(\mathrm{p}=0.49)$, or between patients with a DOD of two, three, or four days $(\mathrm{p}=0,66)$, this variable was grouped as less than 48 hours and more than 48 hours of organ dysfunction in the multivariate analysis. In this analysis, only a DOD of longer than 48 hours was correlated with mortality $(\mathrm{p}=0.004)$ 
interventions within the first 48 hours following organ dysfunction (Group I), and 28 (50\%) had therapeutic interventions initiated after 48 hours (Group 2). Mortality was significantly higher in Group 2 than in Group 1 (82.1\%

Table 3 - Variables associated with mortality in the univariate analysis

\begin{tabular}{|c|c|c|c|c|}
\hline Variable & $\begin{array}{l}\text { All patients } \\
\mathrm{n}=56\end{array}$ & $\begin{array}{l}\text { Survivors } \\
\mathrm{N}=24\end{array}$ & $\begin{array}{c}\text { Non- } \\
\text { survivors } \\
\mathrm{n}=32\end{array}$ & p-value* \\
\hline Age (yrs) & $55.6 \pm 20.7$ & $47.9 \pm 18.5$ & $61.3 \pm 20.8$ & 0.015 \\
\hline $\begin{array}{l}\text { Gender } \\
\text { Male } \\
\text { Female }\end{array}$ & $\begin{array}{l}29(51.8 \%) \\
27(48.2 \%)\end{array}$ & $\begin{array}{c}15 \\
9\end{array}$ & $\begin{array}{l}14 \\
18\end{array}$ & 0.19 \\
\hline APACHE II score & $20.6 \pm 6.9$ & $17.8 \pm 7.5$ & $22.6 \pm 5.6$ & 0.008 \\
\hline SOFA score & $7.9 \pm 3.7$ & $7.5 \pm 4.1$ & $8.2 \pm 3.4$ & 0.52 \\
\hline $\begin{array}{l}\text { Category } \\
\text { Medical } \\
\text { Surgical } \\
\end{array}$ & $\begin{array}{l}26(46.4 \%) \\
30(53.6 \%) \\
\end{array}$ & $\begin{array}{l}13 \\
11\end{array}$ & $\begin{array}{l}13 \\
19 \\
\end{array}$ & 0.42 \\
\hline $\begin{array}{l}\text { Patient location } \\
\text { Hospital ward } \\
\text { ICU/ED } \\
\end{array}$ & $\begin{array}{l}42(75 \%) \\
14(25 \%) \\
\end{array}$ & $\begin{array}{l}14 \\
10\end{array}$ & $\begin{array}{c}28 \\
4 \\
\end{array}$ & 0.015 \\
\hline $\begin{array}{l}\text { Infectious } \\
\text { classification } \\
\text { Community-acquired } \\
\text { Hospital-acquired }\end{array}$ & $\begin{array}{l}16(28.6 \%) \\
40(71.4 \%)\end{array}$ & $\begin{array}{c}9 \\
15\end{array}$ & $\begin{array}{c}7 \\
25\end{array}$ & 0.16 \\
\hline $\begin{array}{l}\text { Sepsis classification } \\
\text { Severe sepsis } \\
\text { Septic shock }\end{array}$ & $\begin{array}{l}20(35.7 \%) \\
36(64.3 \%)\end{array}$ & $\begin{array}{l}11 \\
13\end{array}$ & $\begin{array}{c}9 \\
23\end{array}$ & 0.14 \\
\hline $\begin{array}{l}\text { Number of organs } \\
\text { affected }\end{array}$ & $2.6 \pm 1.2$ & $2.5 \pm 1.4$ & $2.7 \pm 1.1$ & 0.66 \\
\hline $\begin{array}{l}\text { Duration of organ } \\
\text { dysfunction (days) }\end{array}$ & $1.9 \pm 1.9$ & $0.9 \pm 1.4$ & $2.6 \pm 1.9$ & 0.0001 \\
\hline
\end{tabular}

and $32.1 \%$, respectively, $\mathrm{p}=0.0001$ ). No difference was found between the two groups regarding gender, APACHE II score, SOFA score, patient category, presence of septic shock, or compliance with SSC bundles. There was a significant difference in age and antibiotic administration compliance, as defined by the SSC six-hour bundle. Patients in Group 2 were older than those in Group $1(61.1 \pm 19.5$ vs. 50.1 $\pm 20.8, \mathrm{p}=0.05$ ), a fact which could have contributed to the higher mortality rate. Antibiotic compliance was also higher in Group 2 (71.4\% vs. 39.3\%, p= 0.02) (Table 2 and Table 4).

\section{DISCUSSION}

In this study, we were able to show that the time elapsed between onset of organ dysfunction and initiation of therapeutic intervention can be quite long and that this is an important determinant of survival in cases of severe sepsis and septic shock.

Our findings suggest that diagnoses are not being made in a timely manner. A recent survey found that physicians who treat septic patients recognize the difficulty in defining and diagnosing sepsis and are aware that they frequently miss the diagnosis. ${ }^{17}$ Assunção et al. compiled 917 questionnaires completed in 21 Brazilian public, private, and university hospitals that included clinical questions about SIRS, infection, sepsis, severe sepsis, and septic shock definitions. The authors found that as few as $27.3 \%$ of physicians were able to identify a case of sepsis, while $56.7 \%$ could identify a severe sepsis case. ${ }^{18}$ The heterogeneous presentation of a septic patient can render the disease difficult to diagnose, especially for non-intensivists and in patients on inpatient wards. Recognition of sepsis is a key issue and should be a target in educational campaigns.

Table 4 - Interventions received according to severe sepsis recommendations

\begin{tabular}{|c|c|c|c|c|}
\hline Intervention & All patients & Group I & Group II & p-value \\
\hline Blood cultures & $30.4 \%$ & $25 \%$ & $35.7 \%$ & 0.38 \\
\hline Broad-spectrum antibiotics & $55.4 \%$ & $39.3 \%$ & $71.4 \%$ & 0.02 \\
\hline Deliver an initial minimum of $20 \mathrm{ml} / \mathrm{kg}$ of crystalloid & $80.6 \%$ & $85 \%$ & $75 \%$ & 0.45 \\
\hline Vasopressors for hypotension & $91.7 \%$ & $95 \%$ & $87.5 \%$ & 0.42 \\
\hline Achieve CVP of $>8 \mathrm{~mm} \mathrm{Hg}$ & $52.8 \%$ & $45 \%$ & $62 \%$ & 0.30 \\
\hline Achieve $\mathrm{ScvO}_{2}$ of $>70 \%$ & $22.2 \%$ & $20 \%$ & $25 \%$ & 0.72 \\
\hline Low-dose steroids administered for septic shock & $30.6 \%$ & $25 \%$ & $37.5 \%$ & 0.42 \\
\hline Blood glucose control & $51.8 \%$ & $53.6 \%$ & $50 \%$ & 0.79 \\
\hline Inspiratory plateau pressures maintained $<30 \mathrm{~cm} \mathrm{H}_{2} \mathrm{O}$ & $63.6 \%$ & $55 \%$ & $70.8 \%$ & 0.28 \\
\hline 24-hour sepsis bundle ${ }^{\#}$ & $23.2 \%$ & $17.9 \%$ & $28.6 \%$ & 0.18 \\
\hline
\end{tabular}

\#No patients received all interventions recommended by the six-hour sepsis bundle; *Chi square test (Group I vs. Group II); CVP, central venous pressure; $\mathrm{ScvO}_{2}$, central venous oxygen saturation 
In this series, the duration of organ dysfunction prior to intervention was one of two factors related to mortality in a multivariate analysis. Moreover, delayed diagnosis was progressively correlated with higher mortality, i.e. the longer the organ dysfunction, the higher the patient mortality. The risk of death increased 8.73 times for a DOD greater than 48 hours (IC: 95\%, 2.37-2.14). Although this finding may seem intuitive, the extent to which a delay in diagnosis and intervention can directly impact mortality has not previously been clearly demonstrated.

It should be emphasized that interventions that resulted in reduced mortality were all carried out in the early stage of sepsis. Therefore, these results further demonstrate the importance of early treatment. ${ }^{919-22}$ Previous studies using various protocols for hemodynamic optimization failed to reduce mortality, potentially because interventions occurred in a later phase of the process. ${ }^{23,24} \mathrm{~A}$ meta-analysis clearly showed that early, and not late, intervention is associated with decreased mortality. ${ }^{25}$

Another piece of evidence indicating the impact of early treatment is the finding that the mortality rate for patients diagnosed and treated within the first 24 hours after the onset of organ dysfunction was approximately $30 \%$, which is similar to the best rates reported in the literature. ${ }^{13} \mathrm{We}$ carefully analyzed these groups in order to identify other variables that could be responsible for this impressive mortality difference. Interestingly, only age and compliance with the six-hour SSB bundle regarding antibiotic treatment differed between Group $1(<48 \mathrm{~h})$ and Group $2(>48 \mathrm{~h})$. No other classical risk factors - including gender, number of affected organs, number of septic shock patients, category of patients, and SOFA and APACHE II scores - were different. This suggests that the higher mortality rate observed in Group 2 is, indeed, related to the delay in diagnosis. We cannot rule out the possibility that patient age influenced this result, as the patients in Group 2 were significantly older than those in Group 1. However, the age variable was not related to mortality in the multivariate analysis of this population. Moreover, both variables (age and DOD) could be related because the diagnosis of sepsis is often more difficult in older patients, as signs of sepsis or organ dysfunction can easily be misinterpreted and are often attributed to other causes.

It is also interesting that the antibiotic compliance in Group 2 was higher than in Group 1. This higher compliance is not easily explained. Clearly, however, it did not contribute to lowering the mortality rate. This result was unexpected, as compliance was measured from the moment of diagnosis and not the onset of organ dysfunction. In this group of patients, those moments were quite different, and the concept of early antibiotic administration does not apply. The higher compliance could be explained by the fact that Group 2 patients were older and possibly sicker, due to the longer DOD. If so, the severity of the infectious process could have been more obvious to the health care team at the time the diagnosis of sepsis was finally made. However, the small number of patients in this group precludes any conclusion regarding this finding.

It should be highlighted that the precise time of onset of organ dysfunction is easier to define when reviewing retrospective data than it is in clinical practice, even within the context of a best practice model, as the first signs of organ dysfunction can be attributed to causes other than a possible infection. Therefore, in daily bedside practice, health care professionals should not be expected to act at the precise time at which organ dysfunction begins in every case. Given this, our study may have overestimated the duration of organ dysfunction.

Several other limitations must also be mentioned. First, this is a retrospective study, and the power of statistical analysis was affected by the small number of patients enrolled. However, these patients were prospectively included in a multicenter sepsis cost study ${ }^{6}$, and using the same casuistic thus prevented missing patients. We also believe that the chart data for these patients were quite reliable, reducing the negative impact of our retrospective assessment. Nonetheless, larger, prospective cohort studies will be necessary to confirm the finding that lengthy delays often occur in the diagnosis of sepsis and that these delays have a significant, negative impact on mortality.

Second, the mixed nature of our population, including both medical and surgical patients, could have influenced our findings. These patient populations generally show differences in mortality rates. However, it is reasonable to assume that the most important fact demonstrated in our study - that diagnoses of sepsis are often delayed and that this negatively affects mortality - would not be affected by the inclusion of surgical patients. Moreover, the duration of organ dysfunction was not significantly different in this group of patients.

We also included emergency patients in this study, whose duration of organ dysfunction is not always precisely known. However, we believe that clinical manifestations of organ dysfunction would motivate patients to seek treatment immediately in the majority of cases. Given this, the time of admission would seem a reasonable definition for the onset of organ dysfunction. Even if this assumption is incorrect, using this time point as the onset of dysfunction would only decrease mean DOD and would therefore potentially underestimate any differences seen between the two patient groups. It should also be mentioned that only two patients in this study were admitted from the ED. 
Third, when the patients were analyzed by group, the higher age in Group 2 could have influenced the power of the correlation between DOD and mortality. An additional limit to be considered is the fact that most patients did not receive the standard recommended treatment, as evidenced by the low compliance with the six- and 24-hour bundles. Moreover, compliance with the interventions was assessed from the time of diagnosis rather than from the onset of organ dysfunction. Compliance would have decreased further had the latter time point been chosen. However, this does not affect the correlation between time of organ dysfunction and mortality.

Priority must be established to ensure the rapid initiation of appropriate interventions in cases of sepsis. Increasing early detection of organ dysfunction is the first and most fundamental step in achieving this goal. Educational programs should address this problem, and strategies should be developed to improve medical knowledge about diagnosing sepsis.

\section{REFERENCES}

1. Martin GS, Mannino DM, Eaton S, Moss M. The epidemiology of sepsis in the United States from 1979 through 2000. N Engl J Med. 200317;348:1546-54.

2. Vincent JL, Sakr Y, Sprung CL, Ranieri VM, Reinhart K, Gerlach H, et al. Sepsis in European intensive care units: results of the SOAP study. Crit Care Med. 2006;34:344-53.

3. Angus DC, Linde-Zwirble WT, Lidicker J, Clermont G, Carcillo J, Pinsky MR. Epidemiology of severe sepsis in the United States: analysis of incidence, outcome, and associated costs of care. Crit Care Med. 2001;29:1303-10

4. Vincent JL, Abraham E, Annane D, Bernard G, Rivers E, Van den Berghe G. Reducing mortality in sepsis: new directions. Crit Care. 2002;6 Suppl 3:S1-18.

5. Silva E, Pedro Mde A, Sogayar AC, Mohovic T, Silva CL, Janiszewski M, et al. Brazilian Sepsis Epidemiological Study (BASES study). Crit Care. 2004;8:R251-60.

6. Sogayar AMC, Machado FR, Rea-Neto A, Dornas A, Grion C, Lobo SM, Tura B, et al. For the Costs Study Group - Latin American Sepsis Institute: COSTS - multicenter, prospective study to evaluate costs of septic patients in Brazilian intensive care units, Pharmacoeconomics, in press.

7. Teres D, Rapoport J, Lemeshow S, Kim S, Akhras K. Effects of severity of illness on resource use by survivors and nonsurvivors of severe sepsis at intensive care unit admission. Crit Care Med. 2002;30:2413-9.

8. Heyland DK, Hopman W, Coo H, Tranmer J, McColl MA. Long-term health-related quality of life in survivors of sepsis. Short Form 36: a valid and reliable measure of health-related quality of life. Crit Care Med. 2000;28:3599-605.

9. Rivers E, Nguyen B, Havstad S, Ressler J, Muzzin A, Knoblich B, et al. Early goal-directed therapy in the treatment of severe sepsis and septic shock. N Engl J Med. 2001;345:1368-77.

10. van den Berghe G, Wouters P, Weekers F, Verwaest C, Bruyninckx F, Schetz M, et al. Intensive insulin therapy in the critically ill patients. N Engl J Med. 2001;345:1359-67.

11. Ventilation with lower tidal volumes as compared with traditional tidal volumes for acute lung injury and the acute respiratory distress syndrome. The Acute Respiratory Distress Syndrome Network. N Engl J Med. 2000;342:1301-8.

12. Annane D, Sebille V, Charpentier C, Bollaert PE, Francois B, Korach $\mathrm{JM}$, et al. Effect of treatment with low doses of hydrocortisone and fludrocortisone on mortality in patients with septic shock. Jama. 2002;288:862-71.
13. Bernard GR, Vincent JL, Laterre PF, LaRosa SP, Dhainaut JF, LopezRodriguez A, et al. Efficacy and safety of recombinant human activated protein C for severe sepsis. N Engl J Med. 2001;344:699-709.

14. Dellinger RP, Levy MM, Carlet JM, Bion J, Parker MM, Jaeschke R, et al. Surviving Sepsis Campaign: International guidelines for management of severe sepsis and septic shock: 2008. Intensive Care Med. 2008;34:17-60.

15. Institute for Healthcare Improvement: Sepsis [http://www.ihi.org/IHI/ Topics/CriticalCare/Sepsis.html].

16. American College of Chest Physicians/Society of Critical Care Medicine Consensus Conference: definitions for sepsis and organ failure and guidelines for the use of innovative therapies in sepsis. Crit Care Med. 1992;20:864-74.

17. Poeze M, Ramsay G, Gerlach H, Rubulotta F, Levy M. An international sepsis survey: a study of doctors' knowledge and perception about sepsis. Crit Care. 2004;8:R409-13.

18. Assuncao M, Machado F, Akamine N, Cardoso G, Mello P, Telles J, et al. Do they know what is sepsis time? Septic Patients Survey Enrolling Staffs study. Critical Care. 2007;11(Suppl 2):P45.

19. Kumar A, Roberts D, Wood KE, Light B, Parrillo JE, Sharma S, et al. Duration of hypotension before initiation of effective antimicrobial therapy is the critical determinant of survival in human septic shock. Crit Care Med. 2006;34:1589-96.

20. Vincent JL, Bernard GR, Beale R, Doig C, Putensen C, Dhainaut JF, et al. Drotrecogin alfa (activated) treatment in severe sepsis from the global open-label trial ENHANCE: further evidence for survival and safety and implications for early treatment. Crit Care Med. 2005;33:2266-77.

21. Trzeciak S, Dellinger RP, Abate NL, Cowan RM, Stauss M, Kilgannon $\mathrm{JH}$, et al. Translating research to clinical practice: a 1-year experience with implementing early goal-directed therapy for septic shock in the emergency department. Chest. 2006;129:225-32.

22. Jones AE, Focht A, Horton JM, Kline JA. Prospective external validation of the clinical effectiveness of an emergency department-based early goal-directed therapy protocol for severe sepsis and septic shock. Chest. 2007; 132:425-32.

23. Gattinoni L, Brazzi L, Pelosi P, Latini R, Tognoni G, Pesenti A, et al. A trial of goal-oriented hemodynamic therapy in critically ill patients. SvO2 Collaborative Group. N Engl J Med. 1995;333:1025-32.

24. Silva E, Poli de Figueiredo. Sepsis, from bench to bedside. Clinics. 2008;63:109-20.

25. Kern JW, Shoemaker WC. Meta-analysis of hemodynamic optimization in high-risk patients. Crit Care Med. 2002;30:1686-92. 